\title{
Recommendations' Impact on Customer Behavior and Visiting Catering Organizations
}

\author{
Assoc. Prof. Rasa Pauliene \\ Assoc. Prof. Virginijus Tamasevicius \\ MSc. Silvestras Gaivenis \\ Faculty of Economics and Business Administration, \\ Vilnius University, Lithuania
}

Doi: 10.36941/ajis-2020-0oo2

\section{Abstract}

In scientific literature the recommendation definition is often contradictory, which only shows how wide and diverse this field is. The impact of recommendations is becoming increasingly relevant, analyzing different customer target groups, segmented by demographic, geographic, psychographic, and consumer behavior criteria. The aim of the study is to analyze recommendations' significance and impact on customers visiting points of sales. In order to achieve the aim a number of tasks are formulated: first, to form a conceptual model of recommendations' impact on customers behavior and visiting points of sales; second, to carry out a quantitative study in order to identify statistically significant impact of recommendations on visiting catering organizations in integral sample of respondents as well as in different demographic groups. The study presents scientific literature review on social networks, online blogging, recommendation systems' and informal word-of-mouth recommendations' impact on customer behavior and visiting points of sales. Main research methods: comparative analysis of scientific literature, quantitative research - a survey. Summarizing empirical findings of the study it must be concluded that family members, friends and coworkers' recommendations impact visiting catering organizations in the integral sample of respondents. Although advertising on radio, television and outdoor advertising influences the choice of the catering organization, such advertising does not necessarily encourage the frequency of visiting catering organization. However, recommendations on the range of dishes, interior of a catering organization as well as convenient billing and discounts for loyal customers have a positive impact on respondents' visiting catering organizations.

Keywords: E-WOM, WOM recommendation, social media, customer behavior, catering organization, quantitative research

\section{Introduction}

In terms of recommendations it is difficult to single out one definition or theory as in scientific literature recommendations are defined differently, are distinguished theoretical and practical aspects or combinations thereof. In the literature concept of recommendations is often incompatible or even contradictory, which merely shows how wide and diverse the area is. Most often recommendations are related to human communication based on habits, behaviors, opinions or attitudes as well as advancements or innovations. Nowadays marketers become particularly 
interested in better understanding of electronic word-of-mouth (hereinafter e-WOM), because traditional word-of-mouth (hereinafter WOM) as well as previous forms of marketing communication and advertising are might losing their effectiveness (Abubakar et al., 2016). Therefore it is important to understand the salient differences between electronic and traditional WOM (Gupta \& Harris, 2010). According to Hsu et al. (2013) recommendations published in social media are used as advancing tools that help consumers easily find the most consistent information that makes an impact on visiting points of sales, intentions to purchase as well as purchasing decisions. E-WOM communication through social media allows consumers not only to obtain information related to goods and services from the few people they know, but also from a vast geographically dispersed group of people who have experience with relevant products or services (Erkan \& Evans 2016; Lee \& Youn, 2009; Ratchford et al., 2001). Thus the diffusion pattern of e-WOM is much more dispersive and engaging not only closest friends or relatives or neighbors, but large numbers of unknown people located in great social distances (Abubakar et al., 2016; Erkan \& Evans 2016; Gvili \& Levy 2018).

Perception of what recommendation is depends on the context in which the term is used. In a business ecosystem, dominated by permanent changes, a large flow of information and knowledge often encounters such terms as "expectation", "opinion", "trust", "recommendation". As the amount of information increases with the growth of competition, changing customer's needs and expectations, businesses need to adapt to these changes, which means creating new advertising communication, sales promotion tools as well as long-term loyalty programs. Result of effective positive recommendations is increasing customer's perceived value, development of company's activities and as a consequence increased functionality of products or services, reduced costs thus satisfaction of present customers and prospects (Jiménez \& Mendoza, 2013; Mattoo et al., 2008; Xiabo, 2014).

Recommendations are often perceived as self-occurring phenomenon that is difficult to influence, control or manage as they are an integral part of social, economic, technological and other environment (Fill, 2009; Jiménez \& Mendoza, 2013; Xiabo, 2014). The researchers argue that ground of recommendations is cognition, knowledge, expectations and experience. For expression of recommendations are necessary customers' desire, stimulus and ability to communicate knowledge, also to share expectations and experience with others. Some authors argue that increasing impact of recommendations is based on customers' growing demandingness, lack of time to search information although other researchers relate it to a lack of confidence in marketing communication or an excessive amount of advertising (Prasad et al., 2017; Priporas et al., 2015).

Recommendations have several roles in business. First of all, it is one of the main business development engines that help marketers to implement long-term objectives and strengthen competitive advantage. Secondly, recommendations influence the processes as follows: technology and service renewal and development; creation of new supply; new products' development; changes in supply and distribution channels; initiation of changes in corporate governance as well as company human resources management and skills' development (Jobber \& Fahy, 2012).

Impact of recommendations is becoming more and more important in the analysis of different target groups of consumers as well as segmentation based on demographic, geographic, psychographic and consumer behavior criteria. Major authors emphasize importance to research recommendations' impact on younger consumer segments and express necessity to plan marketing activities differently, i.e. introducing new long-term loyalty programs, promoting impulse purchases, etc. (Armstrong et al., 2012; Jalilvand \& Samiei, 2012; Prasad et al., 2017; Seemiller \& Grace, 2017). Recommendations create preconditions for long-term competitive advantage formation as it allows to more successfully meet present consumers' needs and attract new, with significantly lower costs than usual tools of advertising, e.g. TV, radio advertising, outdoor advertising, and etc. This study examines impact of social networks, online blogs, recommendations' systems and informal WOM recommendations on customers' visiting points of sales. The aim of the study is to analyze recommendations' significance and impact on the customer's visiting one or another catering organization. In order to achieve the aim a number of tasks are formulated: 1)To form a conceptual model of recommendations impact on customer's behavior and visiting points of sales; 2)To carry out 
a quantitative study in order to identify statistically significant impact of recommendations on customer's visiting catering organizations in integral sample of respondents as well as in different demographic groups of the respondents.

Problematic of advertising, sales promotion, consumer behavior, and purchasing decisions is widely discussed in scientific literature, however, there is a lack of consequent researches focused on recommendations' impact on consumers choices or preferences associated with various products or services. Researches that analyze and summarize aspects of customers choices would greatly help entrepreneurs in developing long-term marketing plans and deciding on optimal combination of marketing tools that increase sales in existing or newly opened catering organizations, e.g. creating and adjusting menu, creating cozy environment, renewing design, etc. It would also help to maintain a positive public opinion, implement long-term loyalty programs for present clients as well as expand awareness of catering organizations in the segments of prospects.

\section{Theoretical Aspects of Recommendations and Online Customer Behaviour}

\subsection{Social networks}

Social networks daily emanate massive flows of informal information transmitted from consumers to other present or to be consumers. In today's literature, the term e-WOM is often emphasized because the Internet provides an ideal platform for customers to access and share information in a variety "face-to-face" forms of electronic communication, to virtually evaluate products and services, to express opinions and personal experiences, to get immediate feedback from other consumers, etc. (Dellarocas, 2003; Zhaveri, 2013). Consumers' socialization and solidarity in social media take place directly - through online interaction between consumers and indirectly - through peculiar promotion of the products they like (Christodoulides et al., 2012; Forbes \& Vespol, 2013; Wang et al., 2012). Therefore it is very important for manufacturers and sellers to encourage customers' involvement in sharing information as well as evaluating products and services not only in live communication, but also in social media. Consumers are also encouraged to be actively involved by evaluating and describing products and services in the online environment. This activity encourages e-WOM, which through social media helps other customers to make purchasing decisions, share information and user-generated experiences (Kudeshia et al., 2016; Leung et al., 2015; Zhang et al., 2017).

\subsection{Blogs}

In recent years blogging is likely becoming one of the main channels for customers to express their feelings, impressions, ideas and opinions about certain specific events in their everyday lives (Hsu et al., 2013). In this way, customers share information about products and services they like or do not like. The amount of information sent by blogs is enormous - on average goo thousand messages are daily announced (Singer, 2009). Hsu (2013) distinguishes several groups of influence on customers' purchasing decisions: 1)Perceived benefits of recommendations - it is a degree of how much the blog readers believe that the bloggers' recommendations improved quality of their shopping (Davis, 1989); 2)Trust - it is a degree of how much the blog readers think that the blogger and the information provided are reliable (Davis, 1989); 3)Behavior - it is a degree of how much it gives positive emotions to the blog reader in one or another article about shopping; 4)Intention to buy - it is a degree of how many the blog readers think of repurchasing the product or service; 5 )Reputation of a blogger - it is a level of the blog readers' trust in the blogger's honesty and attention demonstrated to readers (Davis, 1989; Fishbein, Ajzen, 1975; Singer, 2009). According to the authors the bloggers' reputation is not the only factor that directly and equally influences intention to buy as each customer perceives reputation and its importance quite differently. 


\subsection{Recommendation systems}

With emergence of the Internet, sales and marketing specialists are increasingly using information technology in business to meet goals of marketing communication and sales plans. Thanks to emergence and consolidation of online shops chain recommendation systems have been developed, which have opened up broad opportunities for customers to evaluate and provide opinions and comments on products or services that they have liked or disliked. Lately, e-WOM communication impact on customers' intention to visit point of sales and make purchasing decisions is consistently growing. Recommendation systems are broadly defined as peculiar filtering information technology, which is commonly used on online stores' websites, helping customers to find products they are likely to find, based on similar customers' choices.

Scientific literature identifies two main types of recommendation systems: oriented to content and oriented to customer behavior. In oriented to content recommendation systems a seller offers to a customer products that are similar to those that the customer has previously chosen, while oriented to customer behavior systems identify the past customers who used to be interested in similar products and offer these products to the current consumer. Informal customer-to-consumer recommendations are "digitized" on the Internet through customers' comments and evaluations thus disseminating signals to new customers about other similarly thinking customers' choices (Pathak et al., 2010; Zhang et al., 2017). Some researchers compare impact of recommendation systems and other customers recommendations on people's decision to buy (Senecal \& Nantel, 2004, Castaño \& Flores, 2019). These researches reveal that recommendation systems are greatly effective in the purchasing decisions of buyers. Recommendation systems are customer-oriented as their "business engine" is customers. An electronic system facilitates the search of products and services for customers. Since such a search is narrowed the system finds products and services that are supposed to be most liked by past customers; it also helps to save time. This explains utmost and positive attitude of most customers to these systems. Over time companies collect more and more information about present and potential customers thus via well-functioning recommendation systems the companies provide customers with better and more accurate information.

\section{Conceptual Approach on Influence of Recommendations on Customer Behavior, Intentions and Decisions}

Customer behavior on the market is driven by certain expectations. Researching customers' expectations it is necessary to take into account all stages that shape customers behavior starting from individual needs recognition, information collection and evaluation, ending with post purchasing behavior if a product or a service has been purchased. Referring to systematic overview of scientific literature several factors influencing customers' expectations might be identified: 1)Experience (i.e. previous experience with the product use); 2)Informal recommendation (i.e. informal other clients' recommendations); 3)Formal recommendation (i.e. personal-selling information which is usually provided by a person - employee of an organization); 4)Price for which the consumer can purchase the product or service; 5)Communication (i.e. advertising communication, dissemination of product information by sales promotion tools); 6)Customers' present and future demand; 7)Image of product or service; and etc.

Before buying a product or service a customer has a certain expectation, i.e. pre-created quality standards and satisfaction with the benefits the customer will get as soon as realizes the value of the product. If the customer's expectations are satisfied, it will affect his or her decision to repurchase the product in the future. Researches usually state that customer's expectations are imaginary and rather subjectively predicted future outcomes, which depends on changes in environmental factors and the customer's behavior in a particular situation. Armstrong et al. (2012) argue that researches should include assessments of interactions between customer's behavior and the customers' expectations. Customers' expectations are not always rational, they may often be inadequate or too high, which 
may result the customers' frustration although the frustration will not necessarily be seller's fault, e.g. the consumer is expecting high quality when buying a cheap product, however, in this case it is often disappointing because higher quality product usually costs more. An organization will try to sell as much as possible while advertising its products, however, in this case customers satisfaction and expectations will depend on how the customer perceives advertising communication, how he or she interprets information, how the customer summarizes and evaluates, how makes purchasing decisions.

Based on systematic literature review including customers behavior, their visiting points of sales also aspects of purchasing decisions and post purchase behavior a conceptual model has been designed, integrating impact of advertising communication, sales promotion and recommendations on customers behavior and intentions (Fig. 1).

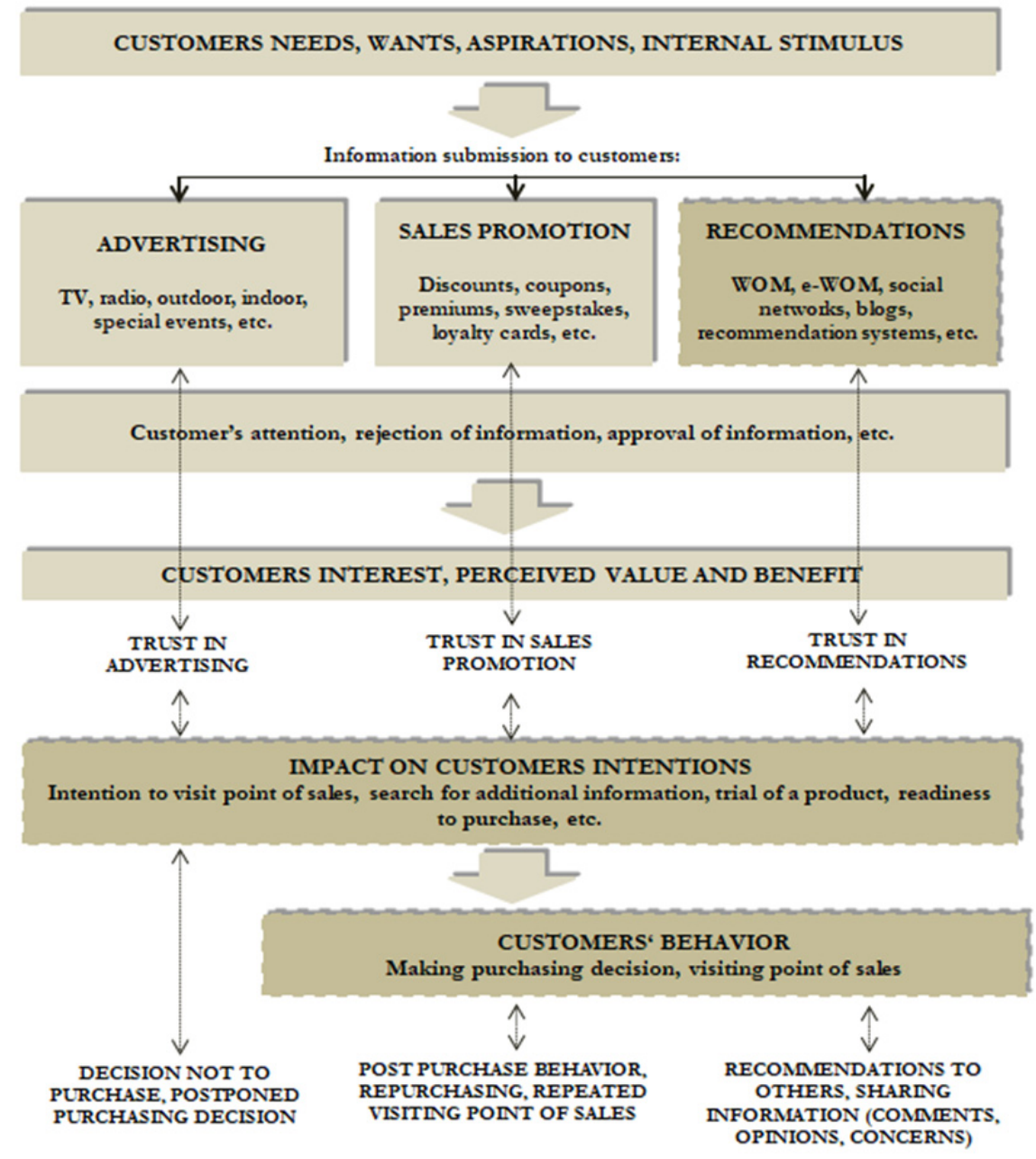

Fig. 1. Conceptual model of information submission and impact of recommendations on customers' behavior, intentions and decisions

Source: Compiled by authors based on systematic literature review 
Over the years customer behavior research is changing, however, some aspects remain very relevant today. Yet Engel et al. (1990) emphasized importance to analyze not only purchasing as an action, but also psychological factors influencing purchasing decision-making and the customer behavior as a whole. The authors argue that while researching customer behavior it is very important to analyze purchasing motives and actions as well as how much the customer's decision has been influenced by unique surroundings or physical environment, other customers opinions, the customer's individual situation, etc. This can help to find answers to questions of how recommendations influence decision to purchase as well as identify other factors affecting the purchasing process. According to Sandhusen (2000) customer behavior is a science of when, why, how and where people buy or do not buy. Engel et al. (1990) customer behavior studies highlight the following aspects: initial incentives, expectations; information transformation; decision-making process; factors influencing the decision. Initial incentives and customers' expectations reveal a beginning and a course of purchasing behavior formation. Emergence of initial incentives and formation of expectations are influenced by psychological, sociological and economic factors as well as the marketing communications implemented by an organization.

In today's society the Internet is becoming a more and more influential tool in shaping customers attitudes on certain products and services. Online communication helps today's customer to share information or communicate with a larger audience, to access the audience easier and faster than it was possible before. Social networks are becoming increasingly popular for online communication as well as blogging systems and systematized recommendation systems are expanding and gaining influential popularity.

\section{Research Methodology, Hypotheses and Respondents Demographic Characteristics}

The aim of the study is to analyze impact of several advertising and sales promotion tools and recommendations on customers visiting points of sales, particularly - catering organizations. The researchers seek to ascertain whether respondents trust recommendations of others and, if so, how big is the impact of recommendations.

Object of the research is an impact of recommendations on the integral sample of respondents as well as different demographic groups of respondents' visiting catering organizations. Tasks of the empirical research: 1)To analyze impact of advertising and recommendations on customers visiting catering organizations; 2) To analyze the impact of advertising and recommendations on visiting catering organizations by analyzing integral sample of respondents; 3)To analyze the impact of advertising and recommendations on visiting catering organizations by analyzing different demographic groups of respondents.

The research aims to identify: what types of recommendations have statistically significant impact on visiting catering organizations?; does belonging to different demographic groups influence respondents' visiting catering organizations? Based on theoretical analysis and statistical reliability calculations 8 hypotheses, reflecting causal relationship between recommendations and visiting catering organizations, have been formulated:

H1 Recommendations from family, friends, co-workers have a positive impact on customers' visiting catering organizations.

H2 Recommendations of bloggers have a positive impact on customers' visiting catering organizations.

$\mathbf{H}_{3}$ Recommendations on social networks have a positive impact on customers' visiting catering organizations.

$\mathbf{H}_{4}$ Advertising communication, i.e. television, radio, outdoor advertising, has a positive impact on customers' visiting catering organizations.

$\mathbf{H}_{5}$ Recommendations on the range of dishes, i.e. new dishes, gourmet dishes, variety of dishes, have a positive impact on customers' visiting catering organizations.

H6 Recommendations about the interior of a catering organization have a positive impact on 
customers' visiting the catering organization.

H7 Recommendations about convenient billing has a positive impact on customers' visiting catering organizations.

H8 Recommendations about discounts for loyal customers have a positive impact on customers' visiting catering organizations.

In order to reach the research tasks a quantitative research method - a survey - has been employed. To obtain accurate answers of respondents' short and clear statements were formulated in the survey questionnaire. To increase instrument validity pre-test was conducted. In pre-test draft questionnaire was subject of qualitative research - revised for formal validation of the research tool. The main goal of this phase was to obviate ambiguous terms, double-barreled questions and poorly formulated ideas. There were twelve participants in the pre-test. Firstly, 7 respondents were asked to complete the survey. As soon as they finished feedbacks from each respondent were collected and the questionnaire modifications based on the feedback have been made. Subsequently, the procedure was repeated with the last 5 respondents, which were given the modified questionnaire. Additionally, the time required for filling in the questionnaire was measured. The average time of filling the questionnaire appeared between 8 and 10 minutes.

The survey was conducted in Lithuania both online and through oral interviews (in this case with hard copies) as the opinion of both Internet users and older people who do not or rarely use the Internet is important. In order to increase the quota of questionnaires being returned participants were offered the opportunity to be introduced to the overall results of the study. The questionnaire has a factual return quota of around $85 \%$ and can be considered as good. In order to maintain anonymity the respondents' questionnaires were given identification numbers.

The survey included 110 respondents, and the gender distribution is fairly even with $58.2 \%$ female and $41.8 \%$ male. Analysis of the respondents' age distribution shows that approximately one third of the respondents (30.9\%) are $19-25$ years old, $18.5 \%$ are respondents $26-35$ years old, $16.1 \%$ are respondents $36-45$ years old, $23.6 \%$ are respondents $46-55$ years old, $10.9 \%$ are respondents 56 years old and older. Majority of the respondents have a university degree (69.1\%), half of the respondents' an average monthly incomes - in the range of 500-10oo euros (49.5\%), about half of the respondents' marital status - single $(52.7 \%)$.

The research data were analyzed using IMB SPSS: Statistical Package for the Social Sciences. Cronbach-alpha statistics were calculated to assess the reliability of the scales and internal consistency of the scales was determined. Scale compatibility with the data was considered as acceptable since Cronbach-alpha is above conventional level of 0.7 (Nunnally, 1978). Non-parametric Spearman correlation coefficient was used to perform correlation analysis as the study assessed the relationships between recommendations and the frequency of the respondents visiting catering organizations. Contingency tables were used to compare impact of advertising and recommendations on visiting catering organizations among different demographic groups of respondents. The Chisquare criterion was used to determine whether respondents' opinions were related to their monthly incomes, age, gender, education. Analyzing respondents responses, results were compared across different demographic groups. The Mann-Whitney criterion was used to compare respondents' assessments in 2 independent groups and the Kruskal-Wallis criterion - in 3 and more groups. A multiple regression model has also been developed to assess the importance of recommendations on respondents' opinions and visiting catering organizations.

\section{Research Results}

Results of the empirical study show that assessment of recommendations of family members impact is related to the respondents visiting catering organizations. Summarizing the results of the recommendations impact assessments and frequency of visits it can be stated that influence of family members' recommendations is statistically significally related to the frequency of the respondents visiting catering organizations in the integral sample of respondents. Based on these results 
hypothesis $\mathrm{H}_{1}$ is accepted because recommendations of friends and co-workers were statistically significantly related to frequency of visiting catering organizations too, however, the research hypotheses $\mathrm{H}_{2}$ and $\mathrm{H}_{3}$ were rejected as the recommendations of bloggers and recommendations of people on social networks are not related to the frequency of visiting catering organizations in the integral sample of respondents.

Analysis of the respondents' opinion about the seen / heard advertisement on television, radio or outdoor advertising about the catering organization revealed that majority of the respondents $(42.73 \%)$ think that the advertisement would give an incentive to visit the advertised catering organization. Meanwhile almost every third respondent $(31.82 \%)$ state that this type of advertising does not affect the frequency of their visits to the advertised catering organization. Although advertising on radio, television and outdoor advertising influences the choice of the catering organization such advertising does not necessarily encourage the frequency of visiting catering organization therefore hypothesis $\mathrm{H}_{4}$ is rejected. It is likely that the frequency of visiting catering organizations is not related to aspects of marketing communication, but might be related to the demographic characteristics of the respondents, e.g. monthly incomes, age, and etc. Analyzing the impact of radio, television and outdoor advertising among respondents with different monthly incomes the variety of opinions was found to be significally related to the respondents' incomes. Based on differences in opinions among different groups of respondents most respondents with the lowest monthly incomes (up to $€ 500$ ) do not notice advertising (44\%), while most respondents with monthly incomes of $€$ 500-100o, also $€ 1001$ and above $(44.4 \%$ and $43.3 \%$ respectively) state that advertising influences their visits to catering organizations.

For testing hypothesis $\mathrm{H}_{5}$ the correlation between recommendations on the range of dishes, i.e. new dishes, gourmet dishes, variety of dishes and the respondents' visiting catering organization has been analyzed. The results showed that recommendations on the range of dishes' assessments are related to the frequency of visits to catering organizations thus the hypothesis $\mathrm{H}_{5}$ is accepted. However, summarizing results of the empirical study it can be stated that the information provided in the recommendations about the interior of the catering organization is not related to the frequency of visits to the catering organizations. In the respondents opinion the information provided in the recommendations might be important, however, it does not influence the frequency of visiting catering organizations, and therefore hypothesis H6 is rejected. Despite of that it is noteworthy that there is a statistically significant relationship between family members' recommendations assessments in the different gender groups of the respondents. According to the assessments of men and women the opinion of family members about the interior of the catering organization is more important for women than for men as $73.9 \%$ of women stated that the opinion of family members is very important, while this proportion is only $26.1 \%$ among men.

The results of the hypotheses $\mathrm{H}_{7}$ and $\mathrm{H} 8$ testing showed that respondents' assessments of recommendations about convenient billing as well as information about discounts for loyal customers are related to the frequency of visiting catering organizations. In this phase of the research the individual questionnaire statements were analyzed to identify the respondents' opinions on cash or card payments as well as loyalty cards and discounts' assessment and their impact on visiting catering organizations. The results showed that the recommendations on the payment options and the discounts offered by the loyalty cards are related to the frequency of the respondent's visiting catering organizations. There was a strong positive and statistically significant correlation between the availability of both cash and bank card assessments and visiting catering organizations therefore hypotheses $\mathrm{H}_{7}$ and $\mathrm{H} 8$ are accepted.

A deeper analysis of different demographic groups of the respondents identified that almost all men as well as almost all women indicate their friends' recommendations as a greatest impact on visiting catering organization (93.5\% and $95.3 \%$, respectively). Men and women are also highly motivated by family members' recommendations $(78.3 \%$ and $90.3 \%$, respectively). Outdoor advertising has the least impact on men and women visiting catering organizations ( $13 \%$ and $17.2 \%$, respectively). To summarize, men and women have very similar views on the impact of advertising as 
well as recommendations of family members, friends and co-workers on visiting catering organizations.

\section{Conclusions and Recommendations}

In scientific literature the recommendation definition is often contradictory, which only shows how wide and diverse this field is. Mostly recommendations are about people's communication based on habits, behaviors, opinions or attitudes, as well as progress, innovations, i.e. something new. However, researchers state that the basis of the recommendations is knowledge, acknowledgement, expectations, own experience. This idea can be supplemented because knowledge, expectations or accumulated experience is yet not a recommendation itself. For a recommendation to succeed it requires the willingness, incentive, and ability of the person recommending to communicate his or her knowledge, share expectations, and tell others about own experience of one or another product (Kudeshia \& Kumar, 2017).

Summarizing empirical findings of the study, it must be concluded that family members, friends and co-workers' recommendations impact visiting catering organizations in the integral sample of respondents. Although advertising on radio, television and outdoor advertising influences the choice of the catering organization such advertising does not necessarily encourage the frequency of visiting catering organization. Recommendations on the range of dishes, interior of a catering organization as well as convenient billing and discounts for loyal customers have a positive impact on respondents' visiting catering organizations. Analysis of different demographic groups of the respondents identified that almost all men as well as almost all women indicate their friends as well as family members' recommendations as a greatest impact on visiting catering organization. Outdoor advertising has the least impact on men and women visiting catering organizations. To summarize, men and women have very similar views on the impact of advertising as well as recommendations of family members, friends and co-workers on visiting catering organizations.

Major researches on both WOM and e-WOM recommendations highlight increasing impact of recommendations on different consumer segments thus express necessity of changes in marketing planning related to long-term loyalty programs, impulsive purchasing decisions, etc. The impact of recommendations is becoming increasingly relevant analyzing different consumer target groups, segmented by demographic, geographic, psychographic, and consumer behavior criteria. Major researches on recommendation aspects highlight increasing impact of recommendations on younger consumer segments thus express necessity of changes in marketing planning related to long-term loyalty programs, impulsive purchasing decisions, etc. In previous studies an impact of recommendations on catering business is analyzed rather episodically and there is no systematic research of the recommendations impact on customers' visiting catering organizations. Such research can help further scientific studies and business practitioners - catering organizations' managers and marketing professionals - to develop catering organization awareness, to create positive image, to successfully implement customer loyalty programs to achieve sales growth and business development goals. It can be assumed that the research can be useful not only for catering organizations but also for other businesses because WOM and e-WOM recommendations' impact tends to constantly increase.

The result of effective positive recommendations usually means increased customer perceived value and benefits the customer gains, increased functionality of goods and services, reduced costs, successful meeting of existing or new needs, wants and expectations of customers and thus a company growth and further business development. It is important for the top management of catering organizations to take this into account for annual planning of their marketing activities as well as choosing effective marketing communication tools for long-term loyalty programs development. In Lithuania, manufacturers of goods and services are not yet using all opportunities to encourage brand advocacy among their customers' communicating on social networks or spreading WOM and thus to reduce impact of negative reviews on further customers' choices. Although online 
shopping in Lithuania is still irregular shoppers look for information about goods and services in online stores before making a decision. Catering organizations should take advantage of such a need and provide customers with as much relevant information as possible about the products and services, their benefits, the identity of the catering organization, their exclusivity, and etc.

\section{Research Limitations and Further Discussion}

Respondents - residents of Lithuania - participated in the survey, the sample of respondents was random (sample - 110 respondents) therefore it is not possible to draw general conclusions about how the recommendations influence customers visiting all catering organizations in Lithuania, e. g. big cities and towns considering population, number of catering organizations in the cities and towns, and etc. The research was carried out only in Lithuania therefore it is not possible to evaluate the research results and the research findings in the international context, however, it can be noted that this empirical study can be seen not only in the context of Lithuanian realities. These realities can be appreciated to the extent that they help to better understand similarities between general global trends and processes in Lithuania.

The study presents conceptual model of the recommendations impact on visiting points of sales as a system of interacting, influencing elements. One of limitations of the research is that relationships and causality between elements was examined mechanistically which was determined by the choice of the research instrument - the quantitative research method, i.e. a survey of random sample of respondents. If interactions between elements are researched synergy effects can be expected, which often means a different quality that cannot always be measured by quantitative research. Qualitative research would extend scientific knowledge of the relationships and interactions between the elements as well as the recommendations' phenomena.

Assessment of impact of recommendations, the impact of recommendations on customers' attitudes and behaviors has always been a difficult object to research as there are no clear criteria. The impact of recommendations is assessed by many researchers according to the effects of those recommendations, i.e. impact on other customers and their intentions. In the absence of clear criteria for assessing impact of recommendations each type of recommendation, e.g. WOM recommendation, e-WOM recommendation, can be represented as a causal chain of many elements and variables as it depends on the researcher's goals. This study is limited to current performance evaluation thus is empirically examining one of many fragments of recommendations impact. The impact of recommendations and the effectiveness of recommendations are also difficult to predict because any specific behavior as well as the customers further actions that have been effected by WOM, e-WOM recommendations may not occur immediately, but only after some time.

\section{References}

Abubakar A., Ilkan M., \& Sahin P. (2016). eWOM, eReferral and gender in the virtual community. Marketing Intelligence E Planning, 34(5), 692-710.

Armstrong G., Kotler P., Harker M., Brennan R. (2012). Marketing: An Introduction. Pearson Education Ltd.

Castaño, R., \& Flores, D. (2019). Consumer Behavior in Emerging Markets. In R. Grosse and K. E. Meyer (Eds.), The Oxford Handbook of Management in Emerging Markets. Oxford University press.

Christodoulides, G., Michaelidou, N., \& Argyriou, E. (2012). Cross-national differences in e-WOM influence. European Journal of Marketing, 46(11/12), 1689-1707.

Davis, F.D. (1989). Perceived usefulness, perceived ease of use, and user acceptance of information technology. MIC Quarterly, 13(3), 319-339.

Dellarocas, C. (2003). The digitization of word of mouth: Promise and challenges of online feedback mechanisms. Management science, 49(10).

Engel, J. F., Blackwell, R. D., Miniard, P. W. (1990). Consumer Behavior. (10th ed.). New York: The Dryden Press.

Erkan, I., \& Evans, C. (2016). The Impacts of Electronic Word of Mouth in Social Media on Consumers' Purchase Intentions. International Conference on Digital Marketing (ICODM2014). 
Fill Ch. (2009). Marketing Communications: Interactivity, Communities and Content. 5th ed. Pearson Education Ltd.

Fishbein, M. \& Ajzen, I. (1975). Belief, Attitude, Intention and Behavior: An Introduction to Theory and Research. Reading MA: Addison-Wesley.

Forbes, L., \& Vespol, E. (2013). Does Social Media Influence Consumer Buying Behavior? An Investigation Of Recommendations And Purchases. Journal of Business E Economics Research, 11(2), 107-112.

Gupta, P., \& Harris, J. (2010). How e-WOM recommendations influence product consideration and quality of choice: a motivation to process information perspective. Journal of Business Research, 63(9), 1041-9.

Gvili, Y., \& Levy, S. (2018). Consumer engagement with eWOM on social media: the role of social capital. Online Information Review, 42(4), 482-505.

Hsu, Ch-L., Judy Ch-Ch. L. \& Chiang, H-S. (2013). The effects of blogger recommendations on customers' online shopping intentions. Internet Research, 23(1), 69-88.

Jalilvand, M.R. \& Samiei, N. (2012). The effect of electronic word of mouth on brand image and purchase intention: an empirical study in the automobile industry in Iran. Marketing Intelligence E Planning, 30(4), 460-476.

Jiménez, F. R., \& Mendoza, N. A. (2013). Too popular to ignore: The influence of online reviews on purchase intentions of search and experience products. Journal of Interactive Marketing, 27(3), 226-235.

Jobber D., Fahy J. (2012). Foundations of Marketing. $4^{\text {th }}$ ed. McGraw Hill Education.

Kudeshia, C., Kumar, A. (2017). Social eWOM: does it affect the brand attitude and purchase intention of brands? Management Research Review, 40(3), 310-330.

Kudeshia, C., Sikdar, P., \& Mittal, A. (2016). Spreading love through fan page liking: a perspective on small scale entrepreneurs. Computers in Human Behavior, 54, 257-270.

Lee, M., Youn, S. (2009). Electronic word of mouth (eWOM): how eWOM platforms influence consumer product judgment. International Journal of Advertising, 28(3), 473-99.

Leung, X. Y., Bai, B., \& Stahura, K. A. (2015). The marketing effectiveness of social media in the hotel industry: a comparison of Facebook and Twitter. Journal of Hospitality E Tourism Research, 39(2), 147-169.

Moore, K. \& Pareek, N. (2010). Marketing: the Basics. - New York: Routledge.

Mattoo, A., Stern, R.M. \& Zanini, G. (2008). Handbook of International Trade in Services. Oxford University Press.

Nunnally, J. C. (1978). Psychometric theory (2 ${ }^{\text {nd }}$ ed.). New York: McGraw-Hill.

Pathak, B., Garfinkel, R., Gopal, R.D., Venkatesan, R. \& Yin, F. (2010). Empirical Analysis of the Impact of Recommender Systems on Sales. Journal of Management Information Systems, 27(2), 159-188.

Prasad, S., Gupta, I., \& Totala, N. (2017). Social media usage, electronic word of mouth and purchase-decision involvement. Asia-Pacific Journal of Business Administration, 9(2), 134-145.

Priporas, C. V., Kamenidou, I., Kapoulas, A., \& Papadopoulou, F. M. (2015). Counterfeit purchase typologies during an economic crisis. European Business Review, 27(1), 2-16.

Ratchford, B. T., Talukdar, D., \& Lee, M. S. (2001). A model of consumer choice of the Internet as an information source. International Journal of Electronic Commerce, 5(3), 7-22.

Sandhusen R. L. (200o). Marketing. New York: Barron's Educational Series, Inc.

Senecal, S. \& Nantel, J. (2004). The influence of online product recommendations on consumers' online choices. Journal of retailing, 80, 159-169.

Seemiller, C. \& Grace, M. (2017). Generation Z: Educating and Engaging the Next Generation of Students. TOC, $22(3), 21-26$.

Singer, A. (2009). Social media,Web 2.0 and internet stats.

Xiaobo, P. (2014). The path of influence of e-WOM on consumer purchase intention- based on electronic commerce in China. Journal of Chemical and Pharmaceutical Research, 6(6), 976-983.

Wang, X., Yu, C. \& Wei, Y. (2012). Social media peer communication and impacts on purchase intentions: a consumer socialization framework.

Zhaveri, H. (2013). Social Networking site for marketing. Proceedings of National Conference on New Horizons in IT, 215-218.

Zhang, T., Omran, B., Cobanoglu, C. (2017). Generation Y's positive and negative eWOM: use of social media and mobile technology. International Journal of Contemporary Hospitality Management, 29(2), 732-761. 